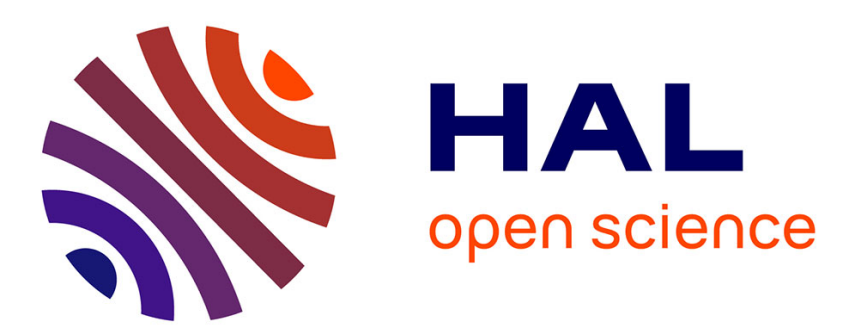

\title{
Gènes majeurs chez la poule (Gallus Gallus) : autres gènes que ceux affectant la taille (1)
}

P. Merat

\section{To cite this version:}

P. Merat. Gènes majeurs chez la poule (Gallus Gallus) : autres gènes que ceux affectant la taille (1).

Productions Animales, 1990, 3 (5), pp.355-368. hal-00895918

\section{HAL Id: hal-00895918 \\ https://hal.science/hal-00895918}

Submitted on 1 Jan 1990

HAL is a multi-disciplinary open access archive for the deposit and dissemination of scientific research documents, whether they are published or not. The documents may come from teaching and research institutions in France or abroad, or from public or private research centers.
L'archive ouverte pluridisciplinaire HAL, est destinée au dépôt et à la diffusion de documents scientifiques de niveau recherche, publiés ou non, émanant des établissements d'enseignement et de recherche français ou étrangers, des laboratoires publics ou privés. 
INRA Prod. Anim., 1990, 3 (5), $355-368$

\section{P. MERAT}

\section{INRA}

Laboratoire de Génétique factorielle 78352 Jouy-en-Josas Cedex

\section{Gènes majeurs chez la poule (Gallus Gallus) : autres gènes que ceux affectant la taille (1)}

\section{Pour l'amélioration génétique des volailles, outre les gènes réduisant la taille, on peut suggérer l'utilité de certains gènes susceptibles d'améliorer le métabolisme des animaux ou leur résistance à certaines maladies. Toutefois, compte tenu des difficultés soulevées par l'incorporation de gènes majeurs dans les programmes de sélection, seuls des gènes à effet assez important peuvent être utilisés.}

Dans un premier article nous avons examiné les effets et l'utilisation possible de gènes réduisant la taille corporelle chez la poule domestique. Le présent article passe en revue d'autres gènes majeurs, à effet visible, métabolique ou sérologique.

\section{1 / Gènes permettant l'identification du sexe des poussins}

Quelques gènes liés au sexe modifiant l'apparence sont utilisés pour identifier le sexe des

\section{Résumé}

Les effets et l'utilité de gènes chez la poule autres que ceux influant sur la taille ont été recherchés. Plusieurs gènes liés au sexe (coloration, emplumement) permettent le sexage à l'éclosion. Le gène " crête en pois " améliore de $2 \%$ le taux de conversion des pondeuses. Plusieurs gènes de dépigmentation du plumage abaissent légèrement le poids, améliorent l'indice de consommation pour la ponte et l'état du plumage. L'allèle albinos lié au sexe apparaît supérieur pour la ponte en forte intensité lumineuse. Le gène "Cou nu " augmente le rendement en viande des poulets ; il amoindrit l'efficacité alimentaire aux températures modérées, mais, au-dessus de $30^{\circ}$, est bénéfique pour la croissance. la viabilité, le poids des oeufs et la reproduction. Il pourrait être utile en climats chauds. Le gène «Frisé » n'a pas d'effets aussi prononcés. L'emplumement lent, utilisé dans des croisements sexables, est lié en race Leghorn à un « gène viral » et augmente le risque d'infection leucosique par l'oeuf. Au locus B (complexe majeur d'histocompatibilité), certains génotypes affectent la résistance à la maladie de Marek, contre laquelle les vaccins ne sont pas totalement efficaces. Un gène responsable d'une mauvaise odeur des oeufs lorsque du tourteau de colza est incorporé dans la ration existe dans certaines populations où son éradication a été envisagée.

L'emploi de facteurs mendéliens peut être indiqué en vue de caractères coûteux à sélectionner directement ou d'environnements non réalisables par le sélectionneur. Les conditions optimales d'utilisation d'un gène nouveau peuvent comporter la correction de certains de ses effets. poussins d'un jour dans des croisements appropriés. C'est le cas du couple allélique $\mathrm{S} / \mathrm{s}^{+}$ (respectivement duvet «argenté», sans pigment rouge à base de phéomélanines, et « doré », avec pigment rouge). Il en est de même du couple K/k (respectivement emplumement tardif et emplumement précoce). Le gène albino lié au sexe $\left(s^{\text {ill }}\right)$ qui est un allèle de $S$ et $s$, peut avoir le même usage (voir plus loin). Comme chez les oiseaux le sexe mâle est homogamétique, dans un croisement permettant le «sexage» des poussins à vue, la lignée paternelle doit posséder l'allèle récessif et la lignée maternelle l'allèle dominant. Cette utilisation est économiquement importante et elle représente la plus ancienne application pratique des facteurs mendéliens en aviculture.

\section{2 / Gène $P$ (crête " en pois ») et efficacité alimentaire}

Les effets associés au gène « crête en pois» (P) sont résumés dans le tableau 1.

Certains chercheurs, comparant des poulets hétérozygotes pour la crête en pois $(\mathrm{P} / \mathrm{p})$ et des poulets à crête simple $\left(\mathrm{p}^{\prime} / \mathrm{p}^{\prime}\right)$ ont constaté un léger effet retard sur la croissance associé au gène $P$, d'autres non. Une faible réduction du poids des femelles adultes en présence de l'allèle $\mathrm{P}$ a aussi été observée, tandis que le nombre d'oeufs pondus, leur poids moyen, la solidité des coquilles n'étaient pas affectés. L'effet le plus intéressant, retrouvé régulièrement dans plusieurs comparaisons, concerne la consom-

(1) Voir première partie dans Productions Animales, 3 , $151-158,1990$. 
mation alimentaire, abaissée d'environ $2 \%$ à ponte et masse d'oeufs égales. Cet effet peut provenir simplement de la réduction extrême de la taille de la crête et des barbillons par le gène $P$, car ces zones non emplumées peuvent laisser passer jusqu'à $15 \%$ des déperditions caloriques de l'oiseau vers le milieu ambiant (Sturkie 1965). Une réduction de $2 \%$ de l'ingestion d'aliment peut correspondre à la diminution du besoin énergétique pour maintenir constante la température de la poule. Cette hypothèse s'accorde aussi avec la corrélation positive trouvée par Bordas et Mérat (1981) entre la taille des barbillons et la fraction « résiduelle » (à poids et ponte égaux) de la consommation alimentaire.

Mentionnons encore une fréquence un peu plus élevée d'ampoules du bréchet chez des poulets $\mathrm{P} / \mathrm{p}^{+}$que chez ceux à crête simple (Hartmann 1972), peut-être du fait d'un emplumement réduit de la région pectorale. D'autre part, les coqs adultes $\mathrm{P} / \mathrm{p}^{\prime}$ ont été trouvés de $8 \%$ plus lourds que leurs frères $\mathrm{p}^{+} / \mathrm{p}^{+}$(crête simple), soit une différence de 250 g. Il n'est pas exclu que cet effet limité au sexe mâle soit d'origine hormonale.

Le gène $P$ ne se trouve que dans des lignées commerciales aviaires de type " chair». Dans ce contexte, deux effets lui sont légèrement défavorables: tendance à une réduction de croissance, apparition plus fréquente d'ampoules du bréchet. Au contraire, les effets associés à cet allèle sur l'efficacité alimentaire et le poids des pondeuses, quoique d'importance limitée, sont favorables, et son incorporation dans des lignées "ponte" pourrait éviter l'écrétage s'il est pratiqué. Dans la perspective de plafonnement futur des progrès de la sélection pour le nombre d'oeufs, de tels avantages peuvent présenter un intérêt accru.

\section{3 / Effets parallèles de quelques gènes de coloration du plumage}

A plusieurs loci comportant un allèle suppresseur d'une pigmentation (eumélanines ou phéomélanines) des effets quantitatifs analogues sont associés. Pour la croissance pondérale, l'effet le plus constant concerne le génotype c/c (blanc récessif) comparé au type coloré $\left(\mathrm{C}^{+} / \mathrm{c}\right)$. Tous les résultats publiés rapportent une croissance légèrement inférieure des animaux "blanc récessif », et la persistance de cet effet à une vingtaine de générations de distance dans une même population a été notée par deux auteurs (revue par Mérat 1990), rendant vraisemblable une action pléiotropique. Une tendance semblable mais moins constante existe pour les gènes $\mathrm{S}$ (suppression des phéomélanines) et I (suppression des eumélanines). Cependant, ces effets sont relativement faibles et entraînent peu de conséquences pratiques (éventuellement une élimination de l'allèle $\mathrm{C}$ des souches " chair» où il peut être masqué par le "blanc dominant»fixé dans ces souches).

Concernant les performances des pondeuses, les comparaisons entre les génotypes coloré et non coloré à quatre loci sont montrées au tableau 2. Une diminution significative du poids à 8 et à 40 semaines accompagne à la fois les phénotypes "blanc récessif " et "blanc dominant $»$. Le premier entraîne aussi une légère réduction du poids moyen de l'oeuf. Des différences non significatives mais de même sens concernent les génotypes non pigmentés aux loci $\mathrm{S}$ et Ig. Le nombre d'oeufs n'est affecté par aucun de ces génotypes, mais la composante "résiduelle» de l'ingestion alimentaire est légèrement (et significativement) plus faible pour les poules à plumage «blanc récessif » et «blanc dominant " comparées à leurs homologues colorées : dans ces deux cas, les poules à plumage non pigmenté consomment moins pour la même production d'oeufs et le même poids corporel. D'autre part, sur quatre années successives la proportion des poules à plumage détérioré après 6 mois de ponte en cages était plus faible parmi les génotypes non pigmentés à chacun des quatre loci, significativement pour deux d'entre eux ( $\mathrm{C}$ et S). La détérioration plus rapide des plumages colorés (par usure ou picage) reste inexpliquée. Elle peut entraîner une consommation alimentaire accrue pour compenser les déperditions caloriques par les zones déplumées. Les poules contrôlées pour la consommation alimentaire au tableau 2 n'étaient d'ailleurs pas les mêmes que celles dont l'état du plumage était noté, et leur plumage était presque toujours intact. Les différences correspondantes entre génotypes pour l'efficacité alimentaire nécessitent donc une autre explication que l'état du plumage, ce qui n'exclut pas que ce dernier accentue les écarts entre génotypes colorés ou non en fin de ponte. On peut se demander si un facteur d'appétit restreint chez différents génotypes supprimant une coloration peut produire en même temps une croissance légèrement retardée et une

Tableau 1. Effets associés au gène “crête en pois " (d'après Mérat 1990).

\begin{tabular}{|l|c|c|}
\hline \multicolumn{1}{|c|}{ Caractères } & $\begin{array}{c}\text { Nombre de } \\
\text { populations } \\
\text { étudiées }\end{array}$ & $\begin{array}{c}\text { Ecart (\%) du génotype } \mathbf{P} / \mathbf{p}^{+} \\
\text {au génotype } \mathbf{p}^{+} / \mathbf{p}^{+}\end{array}$ \\
\hline $\begin{array}{l}\text { Poids à 8 semaines (sexes groupés) } \\
\text { Poids à 40 semaines (femelles) }\end{array}$ & 6 & $-2,4$ à $+1,1$ (médiane $-1,5$ ) \\
$\begin{array}{l}\text { Composante résiduelle (R) de la consommation } \\
\text { alimentaire (femelles) }\end{array}$ & 1 & $-5,4$ à $+0,1$ (médiane $-1,3$ ) \\
Poids à 40 semaines (mâles) & 1 & $-1,8$ \\
\hline
\end{tabular}


Tableau 2. Effets sur plusieurs paramètres quantitatifs associés à des gènes suppresseurs de la pigmentation (d'après Mérat 1990).

\begin{tabular}{|c|c|c|c|c|}
\hline \multirow[b]{2}{*}{ Variable } & \multicolumn{4}{|c|}{$\begin{array}{l}\text { Ecart (\%) du génotype non pigmenté } \\
\text { au génotype coloré pour chaque locus }\end{array}$} \\
\hline & $\begin{array}{c}\mathrm{C} \\
\text { (blanc } \\
\text { récessif) }\end{array}$ & 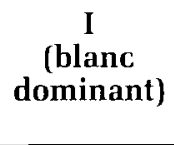 & $\begin{array}{c}\text { S } \\
\text { (argenté } \\
\text { lié au sexe) }\end{array}$ & $\begin{array}{c}\text { Ig } \\
\text { (inhibiteur } \\
\text { du doré } \\
\text { autosomal }\end{array}$ \\
\hline $\begin{array}{l}\text { Poids à } 8 \text { semaines } \\
\text { (sexes groupés) }\end{array}$ & $-2,0^{* * *}$ & $-1,9^{\star \star}$ & $-\quad 0,6$ & $-\quad 0,5$ \\
\hline $\begin{array}{l}\text { Poids des poules } \\
\text { ( } 40 \text { semaines) }\end{array}$ & $-2,5^{\star * *}$ & $-2,6^{* * *}$ & $-\quad 1,2$ & $-\quad 1,2$ \\
\hline Poids moyen des œufs & $-1,3^{\star \star *}$ & $-0,8$ & $-\quad 0,5$ & $-0,9$ \\
\hline $\begin{array}{l}\text { Consommation alimentaire } \\
\text { " résiduelle » des pondeuses } \\
\text { Proportion des poules avec un } \\
\text { plumage intact (après } 6 \text { mois } \\
\text { de ponte) }\end{array}$ & $\begin{array}{l}-3,8^{\star \star} \\
+25,8^{\star \star *}\end{array}$ & $-1,7^{\star}$ & $+27,7^{\star \star \star}$ & $+25,7$ \\
\hline
\end{tabular}

${ }^{*},{ }^{\star *},{ }^{\star \star *}$ : respectivement $\mathrm{p}<0,05 ; \mathrm{p}<0,01 ; \mathrm{p}<0,001$

- poids à 8 semaines et à 40 semaines, poids moyen des œufs : réunion de 23 ans de données (population type « œu brun "; détérioration du plumage : 4 ans de données ; consommation "résiduelle " : 2 comparaisons pour chaque locus.

ingestion alimentaire plus faible durant la ponte. La similarité des effets à des loci distincts, comme la persistance des différences au cours des générations au locus $C$, suggère un effet pléiotropique associé à la coloration.

La connaissance des effets des facteurs de coloration sur la croissance et l'efficacité alimentaire des pondeuses n'a pas de conséquences pratiques dans la mesure où la couleur du plumage est imposée dans les croisements commerciaux; cependant, elle peut être un guide dans le choix de nouveaux croisements.

\section{4 / Le gène d'albinisme imparfait lié au sexe $\left(\mathrm{s}^{\mathrm{a}}\right)$}

Le gène d'albinisme imparfait lié au sexe peut permettre l'identification du sexe des poussins à l'éclosion (Hutt et Cole 1973), de sorte que les effets qu'il pourrait avoir sur les performances économiques méritent d'être examinés.

\section{1 / Effet dans des conditions d'éclairement non spécifiées}

Une mortalité légèrement accrue des embryons albinos en fin d'incubation a été trouvée par certains auteurs, mais non par d'autres; il en est de même de la mortalité juvénile. Dans nos conditions, nous n'avons jamais trouvé d'effet du gène $s^{\text {al }}$ à cet égard (données non publiées). Les effets du gène sil sur la croissance et des caractères de production d'cufs sont résumés au tableau 3. Un retard initial de croissance est caractéristique des poussins albinos, la réduction de poids par rapport aux colorés étant de $10 \%$ à 7 jours, pour tomber à $1,7 \%$ à l'âge de 56 jours dans une population de type « chair» (Silversides et Crawford 1986). Dans une population de pondeuses mi-lourdes, le poids des poulettes albinos comparé à celui de femelles pigmentées de même origine était diminué de $10.5 \%$ à l'âge de 8 semaines, de $6,1 \%$ à 18 semaines et de $1,7 \%$ à 40 semaines (Mérat et al 1986). Un retard moyen de quelques jours était trouvé pour l'âge au premier œuf par Mérat et al (1986) et Silversides et Crawford, (1986). Le poids moyen des cufs des poules $s^{\text {al }}$ était inférieur à celui des poules colorées, de 1,6 et $2,1 \mathrm{~g}$ dans deux essais distincts (Mérat et al 1986). Pour le nombre d'œufs, les mêmes auteurs ainsi que Silversides et al (1987) suggèrent un effet variable associé à l'allèle $s^{\text {il }}$, pouvant être favorable ou non, selon le contexte génétique ou des facteurs d'environnement restant à identifier.

On peut se demander si le retard de la croissance initiale et de la maturité sexuelle ainsi que le poids d'œufs inférieur seraient explicables par les conséquence d'une vision défectueuse des oiseaux albinos. Les avis diffèrent sur ce point. Par ailleurs, Smyth et al (1987) ont observé une similarité de plusieurs effets du gène $s^{\text {il }}$ et d'un albinisme autosomal $\left(c_{i}\right)$ abaissement du taux d'éclosion, raccourcissement du duvet, retard à la résorption du jaune par le poussin faisant penser à une nature pléiotropique de ces effets, et de même pour le gain de poids el le poids des ceufs.

\section{2 / Réponse des pondeuses à l'intensité lumineuse}

Les résultats concernant la ponte suggéraient une réponse différentielle du génotype albinos à certaines composantes de l'environnement. Parmi celles-ci, nous avons examiné le facteur « intensité lumineuse » (Mérat et Bordas 1990). Des poules albinos et normales de même origine ont été réparties en cages individuelles dans 4 cellules, dont 2 recevaient une intensité lumineuse minimale (entre 5 et 10 lux) et les 2 autres une forte intensité (300 à 500 lux selon l'emplacement). Les résultats sont résumés par le tableau 4 et la figure 1 . Les poules normales 
Figure 1. Courbe de ponte jusqu'à 362 jours d'âge de poules $S$ et $S^{a i}$ selon lintensité lumineuse.

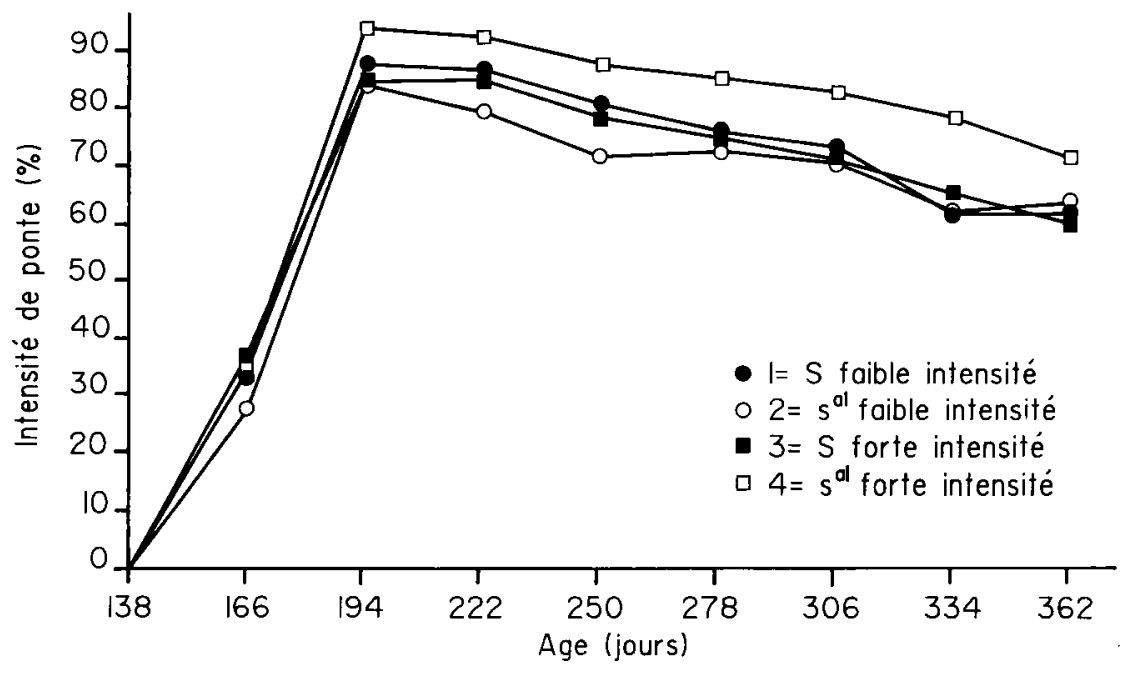

\section{Le gène « albinos » semble avantageux pour la ponte en intensité lumineuse contrôlée.}

Tableau 3. Effets associés au gène albinos lié au sexe $\left(s^{a}\right)$ sur des critères de viabilité, de croissance et de production d'cuufs.

Tableau 4. Performances de poules $s$ et $s^{a t}$ (albinos) à deux intensités lumineuses $(N=157$ au total). conformément à des résultats antérieurs connus. Par contre, les poules albinos se sont révélées un peu inférieures aux poules nonalbinos en faible intensité lumineuse, mais nettement supérieures (d'environ $10 \%$ ) en forte intensité (intensité de ponte: $84 \%$ jusqu'à l'âge de 362 jours contre 72 à $75 \%$ pour les autres groupes). Ce résultat ne peut s'expliquer par un handicap des poules albinos pour la vision, influant sur leur comportement alimentaire. La base physiologique reste à déterminer, un effet hormonal n'étant pas exclu. Une comparaison préliminaire du taux de LH plasmatique par Williams (I.N.R.A. Nouzilly) n'a pas fait ressortir de différence associée au gène $\mathrm{s}^{\mathrm{al}}$. lumière fait penser à la mélatonine impliquée dans la conversion de l'information lumineuse en signal physiologique, ou à des enzymes impliquées dans sa synthèse.

Si nos premiers résultats concernant l'effet de l'intensité lumineuse sur les pondeuses albinos sont généralisables, un intérêt pratique peut ètre envisagé, une ponte améliorée (dans le milieu ad hoc) s'ajoutant à la possibilité de sexage apportée par le gène $\mathrm{s}^{\text {ill }}$. Il restera à préciser davantage les conditions d'élevage (y compris celles du jeune âge) pour l'emploi optimum de pondeuses albinos.

\section{5 / Le gène « $\mathrm{Cou} \mathrm{nu}$ » $(\mathrm{Na})$}

Un intérêt récent s'est éveillé pour le gène "Cou nu " ( $\mathrm{Na}$ ) à cause de la thermotolérance améliorée dont il s'accompagne (revue par Mérat 1986 ; Horst et Rauen 1986 ; Rauen et al 1986).

\section{1 / Croissance, efficacité alimentaire, composition des carcasses et rendement en viande} D'autre part, l'interaction avec le facteur

La revue de Mérat (1986) inclut des comparaisons entre génotypes au locus $\mathrm{Na}$ pour la croissance à diverses températures. Dans trois de celles-ci, les mêmes génotypes étaient répartis dans deux environnements. A $20^{\prime \prime} \mathrm{C}$ ou endessous, les différences pondérales entre génotypes étaient faibles, ou les poulets "Cou nu" étaient inférieurs, et leur efficacité alimentaire était toujours médiocre. A $24-25^{\prime \prime} \mathrm{C}$, croissance et conversion alimentaire ne différaient que de façon négligeable entre les génotypes $\mathrm{Na} / \mathrm{na}$ et na'/na'. Aux approches de $30^{\circ} \mathrm{C}$ et au-dessus, les poulets "Cou nu " homozygotes ou hétéro-

\begin{tabular}{|l|l|}
\hline \multicolumn{1}{|c|}{ Critère } & \multicolumn{1}{c|}{ Effets observés } \\
\hline Mortalité embryonnaire tardive & - légère augmentation ou pas d'effet \\
Viabilité juvénile & - inférieure la première semaine ou pas d'effet \\
Poids corporel & $\begin{array}{l}\text { - retard de la croissance précoce mais compensation après, } \\
\text { d'où pas de différence à 40 semaines }\end{array}$ \\
Efficacité alimentaire (croissance) & - non modifiée \\
Nombre d'œufs & - pas de différence (2 comparaisons) \\
- albinos inférieures (1 comparaison) & - poules albinos supérieures (1 comparaison) \\
Age au premier œuf & - retardé de quelques jours \\
Poids moyen des ceufs & - réduit (1 à 2 g) \\
Conversion alimentaire (ponte) & - non modifiée \\
\hline
\end{tabular}

\begin{tabular}{|c|c|c|c|c|c|}
\hline \multirow[t]{2}{*}{ Critère } & \multicolumn{2}{|c|}{$\begin{array}{l}\text { Faible intensité } \\
\text { (moyenne : } 8 \text { lux) }\end{array}$} & \multicolumn{2}{|c|}{$\begin{array}{c}\text { Forte intensité } \\
\text { (moyenne : } 380 \text { lux) }\end{array}$} & \multirow{2}{*}{$\begin{array}{c}\text { Signification } \\
\text { de } \\
\text { l'interaction } \\
\text { génotype } x \\
\text { traitement }\end{array}$} \\
\hline & $\mathbf{s}$ & $\mathbf{s}^{\mathrm{al}}$ & $\mathbf{s}$ & $\mathbf{s}^{\mathrm{al}}$ & \\
\hline Nombre d'œufs (jusqu'à 362 j.) & 158,3 & 150,6 & 156,9 & 176,0 & ** \\
\hline Intensité de ponte & 75,3 & 72,1 & 74,4 & 83,8 & $* *$ \\
\hline
\end{tabular}


zygotes étaient plus lourds que les poulets na'/na et leur efficacité alimentaire était au moins égale. Les figures 2 et 3 montrent l'écart des génotypes $\mathrm{Na} / \mathrm{Na}$ et $\mathrm{Na} / \mathrm{na}^{2}$ en $\%$ de la valeur moyenne des homozygotes $\mathrm{na}^{+} / \mathrm{na}^{+}$ selon la température d'élevage après l'âge de 4 semaines, respectivement pour le poids corporel et le taux de conversion alimentaire.

Le rendement des carcasses est amélioré de deux façons par le gène $\mathrm{Na}$ indépendamment de la température (Mérat 1986). La réduction du plumage (d'environ $30 \%$ pour $\mathrm{Na} / \mathrm{na}^{+}$et $40 \%$ pour $\mathrm{Na} / \mathrm{Na}$ ) améliore le rendement à l'abattage de 1,5 à $2 \%$ pour le génotype hétérozygote et de 2,5 à $3,0 \%$ pour le génotype « Cou nu " homozygote. Il y a aussi une augmentation du rendement en viande des carcasses plumées et éviscérées. L'avantage de $\mathrm{Na} / \mathrm{na}^{+}$sur na' /na à cet égard va de 1,8 à $7,1 \%$ chez les mâles et de 0,8 à $5,1 \%$ chez les femelles selon la population examinée. Ceci résulte d'une proportion plus élevée de tissu musculaire chez les oiseaux "Cou nu », essentiellement dans la région pectorale. Nous n'avons pas trouvé de différence entre l'hétérozygote « Cou nu» et le type emplumé na'/na' quant au pourcentage de graisse abdominale, mais il y avait relativement moins de graisse intermusculaire et souscutanée chez les poulets " Cou nu ». Ceci paraît en accord avec une autre étude qui a montré un taux de lipides corporels totaux abaissé chez les poulets de chair « Cou nu».

\section{2 / Ponte et efficacité alimentaire pour la production d'œufs}

Les résultats revus par Mérat (1986), Horst et Rauen (1986) et Rauen et al (1986) montrent une réponse différente des génotypes « Cou $\mathrm{nu} \gg(\mathrm{Na} / \mathrm{Na}$ et $\mathrm{Na} / \mathrm{na}$ ) et normaux aux températures élevées. Le tableau 5 fait apparaître les écarts des génotypes «Cou nu » à la moyenne du génotype $\mathrm{na}^{+} / \mathrm{na}^{+}$à deux températures dans quatre expériences.

Les nombres d'oeufs aux températures modérées ne sont pas affectés par le gène « Cou nu ». A température élevée, les poules «Cou nu », surtout dans l'expérience 4, paraissent avoir une intensité de ponte plus élevée que les autres. Dans les expériences 1 et 2 , à $20^{\circ} \mathrm{C}$, le poids corporel adulte était moindre chez les poules «Cou nu», surtout les homozygotes, que chez des poules entièrement emplumées, la tendance étant inversée au-dessus de $30^{\circ} \mathrm{C}$. En conséquence, quoique le rapport du poids de l'oeuf au poids du corps soit plus élevé en présence du gène $\mathrm{Na}$ à toute température, l'augmentation du poids moyen des oeufs chez les génotypes $\mathrm{Na} / \mathrm{Na}$ et $\mathrm{Na} / \mathrm{na}$ comparés à na $/ \mathrm{na}^{+}$est plus faible à température modérée qu'aux fortes températures où elle atteint 3 à 4 g pour l'homozygote « Cou nu ». La tendance pour le nombre d'oeufs est la même. Concernant l'efficacité alimentaire, pour les femelles "Cou nu " au-dessus de $30^{\circ} \mathrm{C}$ la composante " résiduelle » de la consommation (indépendante du poids corporel et de la ponte) n'est pas plus élevée que chez les poules $\mathrm{na}^{+} / \mathrm{na}^{+}$, alors qu'en environnement tempéré cette variable est augmentée à cause des déperditions
Figure 2. Poids à 8 ou 10 semaines pour des

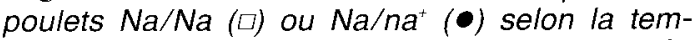
pérature ambiante (écarts \% à na $/ n a^{+}$; d'après Mérat 1990).

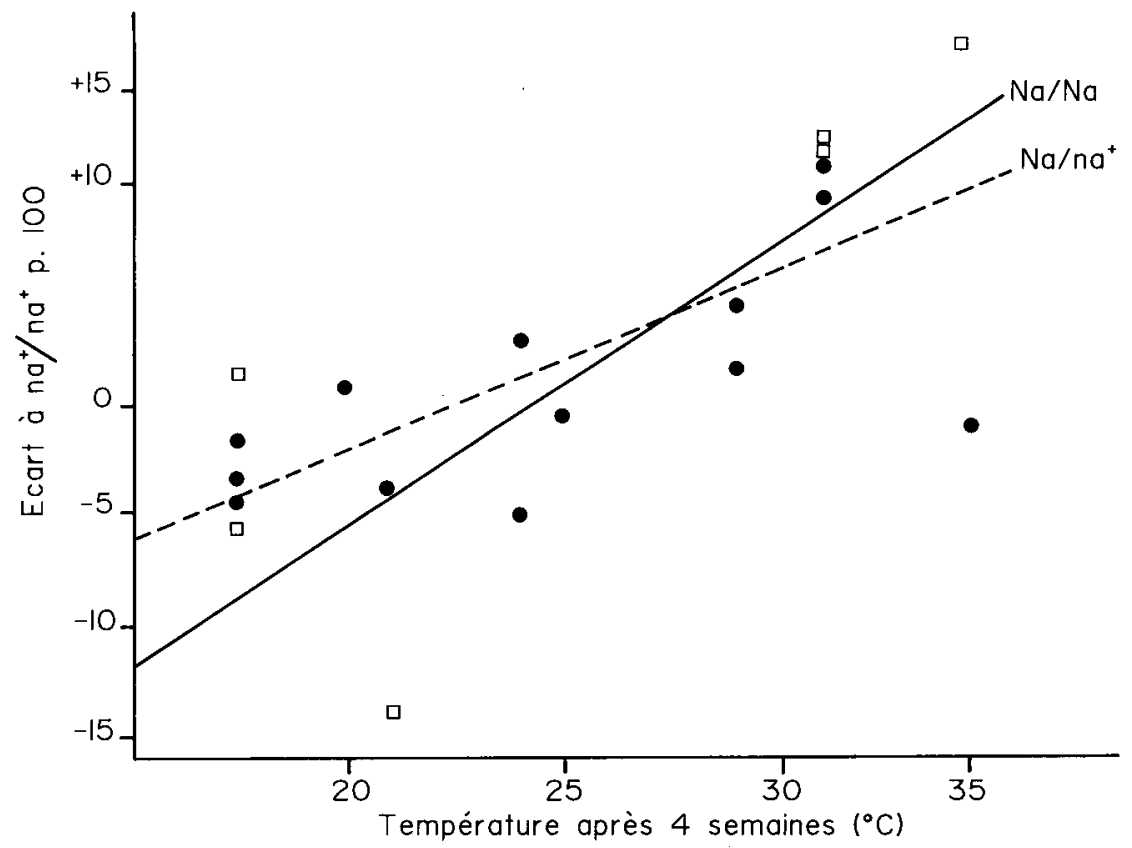

Figure 3. Conversion alimentaire (aliment/gain de poids) pour des poulets $\mathrm{Na} / \mathrm{Na}(\square)$ ou $\mathrm{Na} / \mathrm{na}^{+}(\bullet)$ âgés de 8 ou 10 semaines selon la température ambiante (écarts \% à nat/na'; d'après Mérat 1990).

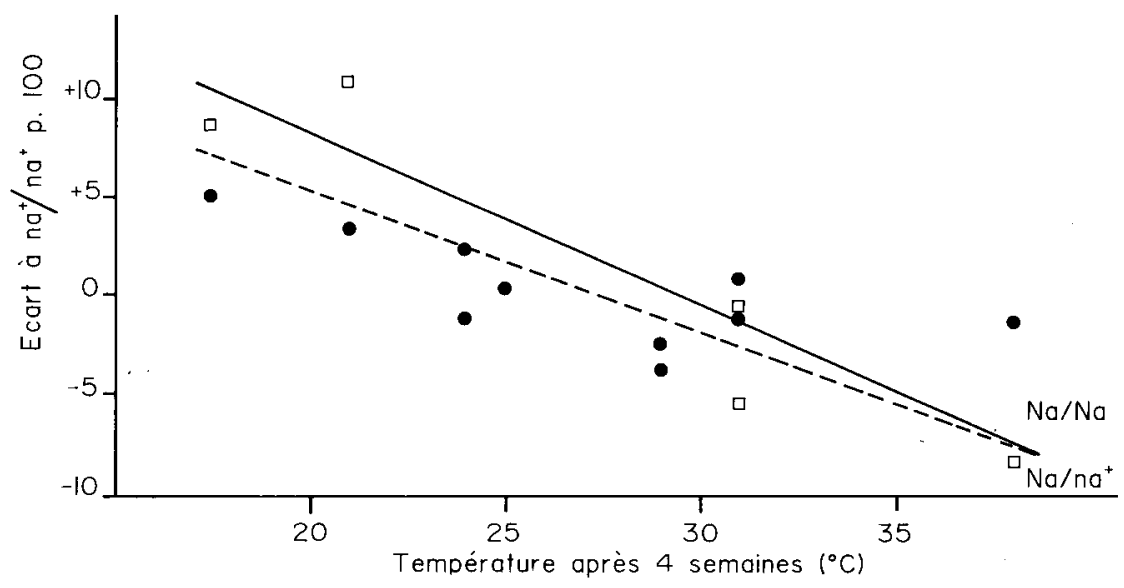

caloriques plus grandes des animaux « Cou nu »: cette plus grande consommation alimentaire des poules «Cou nu» à ponte et poids égaux en conditions tempérées est presque compensée par le poids corporel légèrement réduit chez les hétérozygotes $\mathrm{Na} / \mathrm{na}^{\prime}$, mais chez les homozygotes $\mathrm{Na} / \mathrm{Na}$ la compensation n'est que partielle. Par contre, au-dessus de $30^{\circ} \mathrm{C}$, l'efficacité alimentaire est toujours supérieure pour les pondeuses « Cou nu ».

Le pourcentage d'oeufs cassés ou fêlés n'était pas significativement affecté par le génotype au locus $\mathrm{Na}$ dans les expériences citées. Cependant, les valeurs obtenues suggèrent un léger désavantage du génotype $\mathrm{Na} / \mathrm{Na}$ aux plus basses températures et un léger avantage de ce même génotype aux températures les plus élevées. 
Tableau 5. Comparaison entre génotypes au locus Na pour des critères de production d'œufs et d'efficacité alimentaire à deux températures dans 4 expériences. Données exprimées en écarts (\%) à $n a^{+} / n a^{+}$.

\begin{tabular}{|c|c|c|c|c|c|c|}
\hline \multirow{2}{*}{ Critère } & \multicolumn{6}{|c|}{ Expérience (1) et génotypes } \\
\hline & $\mathrm{Na} / \mathrm{Na}$ & $\mathrm{Na} / \mathrm{na}^{+}$ & $\mathrm{Na} / \mathrm{na}$ & $\mathrm{Na} / \mathrm{na}^{+}$ & $\begin{array}{c}3 \\
\mathrm{Na} / \mathrm{na}^{+}\end{array}$ & $\begin{array}{c}4 \\
\mathrm{Na} / \mathrm{na}^{+}\end{array}$ \\
\hline & \multicolumn{6}{|c|}{ Lot à température modérée } \\
\hline \multirow{5}{*}{$\begin{array}{l}\text { Poids adulte } \\
\text { Nombre d'œufs } \\
\text { Poids moyen des œufs } \\
\text { Efficacité alimentaire } \\
\text { (g œuf / g aliment) }\end{array}$} & $-10,5$ & $-6,1$ & $-13,9$ & $-\quad 5,9$ & - & - \\
\hline & $-\quad 3,8$ & $-1,1$ & $-\quad 3,3$ & $+\quad 2,0$ & $-\quad 1,8$ & $-\quad 1,7$ \\
\hline & $+4,4$ & $+0,4$ & $+1,4$ & $+2,3$ & $+1,0$ & $+1,3$ \\
\hline & $-8,3$ & $+8,5$ & $+6,8$ & $+10,3$ & $-\quad 3,3$ & $-3,9$ \\
\hline & \multicolumn{2}{|c|}{$\left(31^{\circ} \mathrm{C}\right)$} & \multicolumn{2}{|c|}{$\begin{array}{l}\text { Lot à température élevée } \\
\qquad\left(31^{\circ} \mathrm{C}\right)\end{array}$} & $\left(32^{\circ} \mathrm{C}\right)$ & $\left(32^{\circ} \mathrm{C}\right)$ \\
\hline Poids adulte & $+5,5$ & $+3,4$ & $+\quad 0,3$ & $+0,3$ & - & - \\
\hline Nombre d'œufs & $+4,7$ & $+2,2$ & $+2,4$ & $-\quad 0,6$ & $+\quad 4,8$ & $+16,2$ \\
\hline Poids moyen des œufs & $+9,2$ & $+6,2$ & $+7,1$ & $+2,3$ & $+3,0$ & $+6,7$ \\
\hline $\begin{array}{l}\text { Efficacité alimentaire } \\
\text { (g œuf / g aliment) }\end{array}$ & $+\quad 0,3$ & $-0,8$ & $+13,4$ & $+7,4$ & 1,3 & $+9,9$ \\
\hline
\end{tabular}

(1) Expérience $1:$ Dw+ type pondeuse mi-lourde (Bordas et al 1980) Expérience $2: \mathrm{dw}$ type pondeuse mi-lourde (Bordas et Mérat 1984) Expériences 3 et 4 : Dw $w^{4}$ tvpes mi-lourd et léger (Rauen et al 1986) (références citées dans Mérat 1990).

Le gène «Cou nu » améliore

la croissance

la viabilité,

le poids des aufs

et les performances

des reproductrices à température élevée.
A une température constante de $25^{\circ} \mathrm{C}$, aucun effet significatif n'a été trouvé associé aux génotypes $\mathrm{Na} / \mathrm{Na}$ et $\mathrm{Na} / \mathrm{na}^{+}$pour le poids corporel, le nombre d'oeufs et l'indice de consommation pour la ponte (tableau 6). Le poids moyen et la masse d'oeufs sont augmentés comme aux autres températures. Fraga et al (1987), à des températures ambiantes voisines en moyenne, observent des résultats similaires, ainsi qu'une meilleure solidité des coquilles pour les poules $\mathrm{Na} / \mathrm{na}^{\prime}$.

Une interaction apparaît entre les effets des gènes $\mathrm{Na}$ et dw. Dans l'expérience 2 (tableau 5) concernant une lignée naine, ainsi que dans des résultats antérieurs (Mérat 1986), l'efficacité alimentaire aux températures modérées n'était pas détériorée même pour le génotype $\mathrm{Na} / \mathrm{Na}$ comparé à na /na'. La différence avec le résultat de l'expérience 1 utilisant des poules non naines ( $\left.\mathrm{Dw}^{-}\right)$, correspond au fait que l'augmentation de la consommation alimentaire "résiduelle » associée aux génotypes $\mathrm{Na} / \mathrm{Na}$ et $\mathrm{Na} / \mathrm{na}^{+}$est limitée lorsque le gène dw est présent. D'autre part, dans une lignée naine à 23 24 "C (Mérat non publié), le génotype $\mathrm{Na} / \mathrm{na}^{+}$ avait un nombre d'oeufs supérieur de $5,5 \%$ au génotype normalement emplumé à l'âge de 39 semaines. Ceci joint aux données du tableau 6 suggère que dans une population nanifiée et à des températures ambiantes modérément chaudes le génotype hétérozygote $\mathrm{Na}$ / na' est avantageux pour la production d'oeufs.

Rauen et al (1986) ont noté que l'avantage du gène $\mathrm{Na}$ pour la ponte en ambiance chaude concerne spécialement la persistance de la ponte et est plus marqué dans des lignées milourdes que chez des pondeuses légères.

Tableau 6. Comparaison entre génotypes au locus Na pour des critères de production d'œufs et d'efficacité alimentaire à $25^{\circ} \mathrm{C}$; écart \% à la moyenne du génotype na*/na+ (d'après Mérat 1986).

\begin{tabular}{|c|c|c|c|c|}
\hline \multirow{3}{*}{ Critère } & \multicolumn{4}{|c|}{ Expérience (1) } \\
\hline & \multicolumn{2}{|c|}{1} & \multicolumn{2}{|c|}{2} \\
\hline & $\mathrm{Na} / \mathrm{Na}$ & $\mathrm{Na} / \mathrm{na}^{+}$ & $\mathrm{Na} / \mathrm{Na}$ & $\mathbf{N a} / \mathbf{n a}^{+}$ \\
\hline Poids corporel & $-3,3$ & $+1,2$ & $+\mathbf{0 , 2}$ & $+0,6$ \\
\hline Nombre d'œufs & $-2,4$ & $+2,6$ & $+2,9$ & $+5,3$ \\
\hline Poids moyen des œufs & $+1,8$ & $+2,7$ & $+2,5$ & $+1,4$ \\
\hline Masse d'œufs & $+0,3$ & $+6,9$ & $+8,6$ & $+6,9$ \\
\hline $\begin{array}{l}\text { Efficacité alimentaire } \\
\text { (g œuf / g aliment) }\end{array}$ & $-1,7$ & $+1,4$ & $-1,2$ & $-1,5$ \\
\hline
\end{tabular}

(1) Expériences 1 et 2 : poules naines ( $\mathrm{d} w$ ), type pondeuse mi-lourde. 
Tableau 7. Fertilité et taux d'éclosion de poules "cou nu " ou normalement emplumées à température élevée $\left(31^{\circ} \mathrm{C}\right)$ ou modérée $\left(21^{\circ} \mathrm{C}\right)$ (d'après Mérat et al 1989).

\begin{tabular}{|c|c|c|c|c|}
\hline \multirow[b]{2}{*}{$\begin{array}{c}\text { Expérience } \\
\text { Génotype des poules }\end{array}$} & \multicolumn{4}{|c|}{ Performances de reproduction } \\
\hline & $\begin{array}{l}\text { Tempéi } \\
\text { \% éclos/ } \\
\text { fertiles }\end{array}$ & $\begin{array}{l}\text { élevée } \\
\text { \% éclos/ } \\
\text { incubés }\end{array}$ & $\begin{array}{l}\text { Tempéra } \\
\text { \% éclos/ } \\
\text { fertiles }\end{array}$ & $\begin{array}{l}\text { modérée } \\
\% \text { éclos/ } \\
\text { incubés }\end{array}$ \\
\hline $\begin{array}{l}\text { Expérience } 1 \\
\mathrm{Na} / \mathrm{Na} \\
\mathrm{na}^{+} / \mathrm{na}^{+}\end{array}$ & $\begin{array}{l}89,2 \\
69,8\end{array}$ & $\begin{array}{l}83,7 \\
51,5\end{array}$ & $\begin{array}{l}88,8 \\
83,8\end{array}$ & $\begin{array}{l}84,1 \\
75,5\end{array}$ \\
\hline $\begin{array}{l}\text { Expérience } 2 \\
\mathrm{Na} / \mathrm{Na} \\
\mathrm{na}^{+} / \mathrm{na}^{+}\end{array}$ & $\begin{array}{l}80,6 \\
72,0\end{array}$ & $\begin{array}{l}74,6 \\
61,2\end{array}$ & $\begin{array}{l}86,5 \\
78,9\end{array}$ & $\begin{array}{l}82,1 \\
74,8\end{array}$ \\
\hline
\end{tabular}

- Les poules de même génotype aux deux températures étaient inséminées avec le sperme mélangé des mêmes coqs. - Tous les embryons étaient $\mathrm{Na} / \mathrm{na}$.

\section{3 / Fertilité et taux d'éclosion}

Smith et Lee (1977) n'ont pas observé de différence entre coqs $\mathrm{Na} / \mathrm{na}^{+}$et $\mathrm{na}^{+} / \mathrm{na}^{+}$pour la fertilité et les caractéristiques de qualité du sperme. Hammade et al (1987) ont comparé des mâles en cages individuelles à $18^{\circ} \mathrm{C}$ et $30^{\circ} \mathrm{C}$; ils ont obtenu à plusieurs âges un volume et un nombre de spermatozoïdes par éjaculat plus élevé pour les coqs $\mathrm{Na} / \mathrm{Na}$ que pour les coqs $\mathrm{na}^{+} / \mathrm{na}^{+}$avec des valeurs intermédiaires pour I'hétérozygote et sans interaction génotype $\mathrm{x}$ température. Toutefois, il n'est pas apparu de différence significative de fertilité entre génotypes.

Une augmentation de la mortalité en incubation (jusqu'à $10 \%$ en lignées pures) a été trouvée associée aux génotypes embryonnaires $\mathrm{Na}$ / $\mathrm{Na}$ et $\mathrm{Na} / \mathrm{na}^{-}$par Crawford (1977) et d'autres auteurs.

Concernant les effets du gène Na sur les performances de la reproductrice selon la température ambiante la comparaison de Mérat et al (1989) a montré qu'à une température constante de $31^{\circ} \mathrm{C}$, le taux de fertilité et d'éclosion des poules à plumage normal est considérablement abaissé par rapport à un témoin à $20^{\circ} \mathrm{C}$, mais les poules « Cou nu » ne sont que peu ou pas affectées. (tableau 7). Le protocole expérimental permettait d'éliminer un effet du génotype des mâles reproducteurs et des embryons. Ce résultat renforce l'intérêt du gène $\mathrm{Na}$ pour une production en zones chaudes, mais il peut également servir de modèle pour une étude physiologique de l'influence des températures élevées sur les performances des reproductrices, moins étudiée que pour le mâle.

\section{4 / Mortalité}

La mortalité post-embryonnaire n'est pas différente pour les poussins « Cou nu » ou normalement emplumés, excepté lors d'un stress de chaleur au-dessus de $40^{\circ} \mathrm{C}$. Smith et Lee (1977) ont obtenu dans ce cas des taux de survie de $51,4 \%$ et $38,8 \%$ respectivement pour les oiseaux $\mathrm{Na} / \mathrm{na}^{\prime}$ et na $\mathrm{na}^{+}$. Dans une expérience similaire sur des poussins âgés de
2 jours (Mérat 1986), les pourcentages de survie des mêmes génotypes étaient respectivement de 59,3 et $33,3 \%$.

La mortalité des adultes ne présente pas de différence entre types « Cou nu » ou normalement emplumé autour de $20^{\circ} \mathrm{C}$. A $30^{\circ} \mathrm{C}$ ou plus, la mortalité était plus basse pour les pondeuses « Cou nu » hétérozygotes que pour les poules comparables à plumage complet (Rauen et al 1986). Une différence de même sens existait à $25^{\prime \prime} \mathrm{C}$ entre des lignées nanifiées différant pour leur génotype au locus $\mathrm{Na}$ (tableau 8). Des résultats de Barrio et al (1987) indiquent une fréquence moindre du cannibalisme en présence du gène $\mathrm{Na}$, ce qui peut aussi se répercuter sur le taux de survie.

Le gène " cou nu » influe favorablement sur diverses performances en conditions climatiques chaudes.

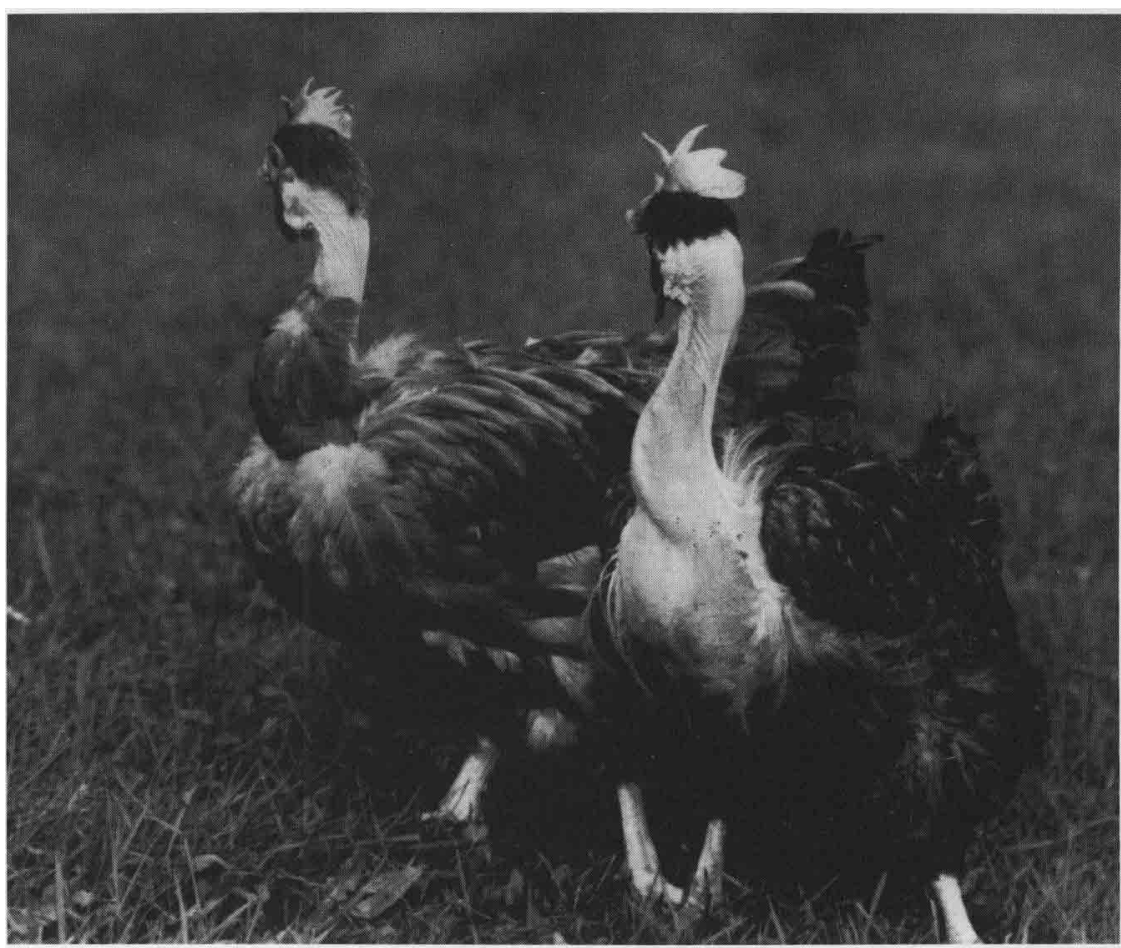


Tableau 8. Mortalité adulte: comparaison des génotypes au locus $\mathrm{Na}$ à différentes températures ambiantes.

\begin{tabular}{|c|c|c|c|c|c|c|}
\hline \multirow{3}{*}{$\begin{array}{l}\text { Référence } \\
\text { Température }\end{array}$} & \multicolumn{6}{|c|}{ Génotype } \\
\hline & \multicolumn{2}{|c|}{$\mathrm{Na} / \mathrm{Na}$} & \multicolumn{2}{|c|}{$\mathrm{Na} / \mathrm{na}^{+}$} & \multicolumn{2}{|c|}{$\mathrm{na}^{+} / \mathbf{n a}^{+}$} \\
\hline & n & Mortalité \% & n & Mortalité \% & $\mathbf{n}$ & Mortalité \% \\
\hline $\begin{array}{l}\text { Rauen (1985) } \\
\text { Expérience 1 : témoin } \\
\qquad 32^{\circ} \mathrm{C}\end{array}$ & & & $\begin{array}{l}220 \\
215\end{array}$ & $\begin{array}{r}5,9 \\
14,4\end{array}$ & $\begin{array}{l}259 \\
259\end{array}$ & $\begin{array}{r}5,8 \\
24,0\end{array}$ \\
\hline $\begin{array}{c}\text { Expérience 2: témoin } \\
32^{\circ} \mathrm{C}\end{array}$ & & & $\begin{array}{l}233 \\
230\end{array}$ & $\begin{array}{l}2,1 \\
8,3\end{array}$ & $\begin{array}{l}248 \\
251\end{array}$ & $\begin{array}{r}3,6 \\
20,9\end{array}$ \\
\hline $\begin{array}{l}\text { Boichart et Mérat } \\
\text { (non publié) } \\
\text { Température modérée } \\
\left(25^{\circ} \mathrm{C}\right)\end{array}$ & 515 & 5,4 & 563 & 8,7 & 564 & 10,5 \\
\hline
\end{tabular}

tre à la tête de prendre plus facilement des positions défectueuses. La proportion réduite de lipides sous-cutanés et intermusculaires (voir Mérat 1986) chez les poussins « Cou nu » pourrait résulter de l'utilisation d'une part plus grande de l'apport énergétique pour la thermorégulation. En ce qui concerne les mâles « Cou nu » adultes, le léger abaissement de leur température interne peut contribuer à leur production de sperme plus élevée, sachant que les hautes températures ont une influence négative à cet égard (De Reviers 1982). Quant au poids des oeufs, on remarque que deux autres gènes supprimant ou réduisant le plumage, sc (Abbott 1958, Abbott et Asmundson 1962) et K" (Sones 1975) sont associés à une augmentation de plusieurs grammes de ce poids.

Les hypothèses ci-dessus sont schématisées dans la figure 4 .

Figure 4. Liens de causalité supposés entre les effets (+ ou -) associés au gène $\mathrm{Na}$.

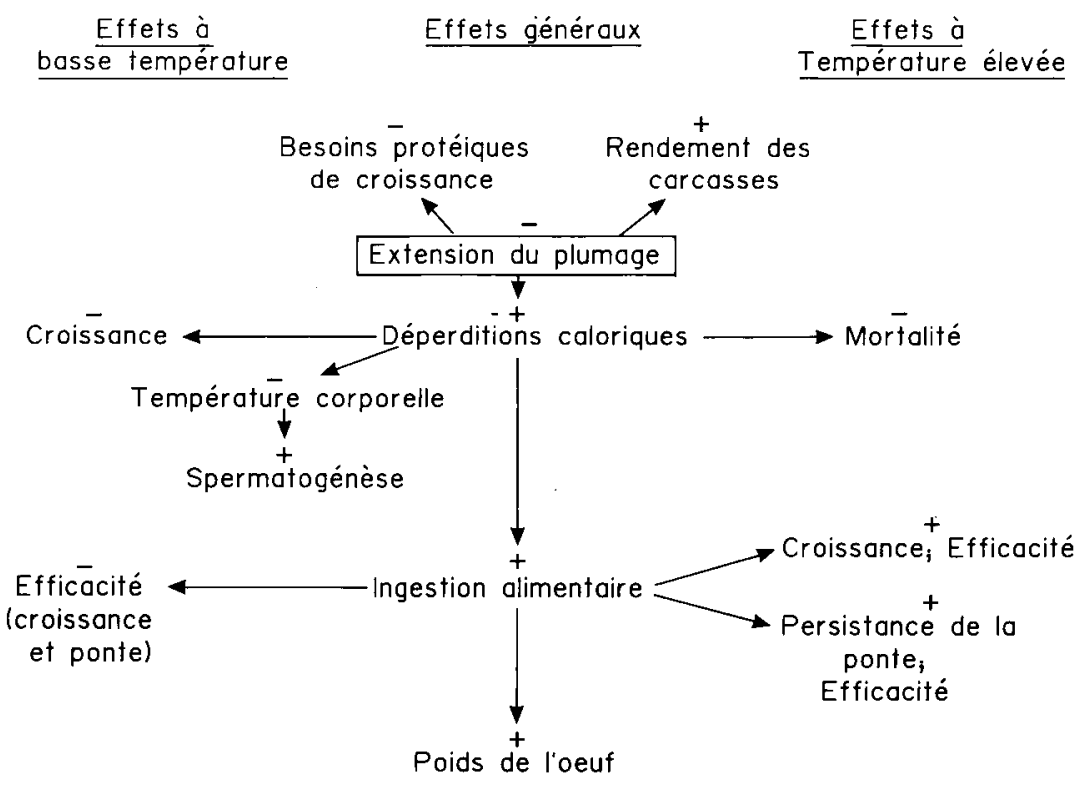

\section{5 / Interprétation des effets}

La réduction des pterylies induite par le gène $\mathrm{Na}$ n'est pas expliquée, mais beaucoup des effets secondaires s'interprètent à partir de cette réduction, et tout d'abord l'augmentation du rendement à l'abattage après plumage. D'autres conséquences dérivent des déperditions caloriques à travers une plus grande surface non couverte de plumes. Herremans et al (1988) l'ont confirmé par la mesure des échanges énergétiques pour les génotypes au locus $\mathrm{Na}$ à divers régimes de température. La consommation alimentaire est aussi augmentée par l'allèle $\mathrm{Na}$ à toute température, et il semble possible que ceci rende compte du poids de l'oeuf accru par suite d'une ingestion plus importante de protéines ou autres matériaux constitutifs.

Aux températures modérées ou basses, cette surconsommation associée à un besoin énergétique plus élevé se traduit par une efficacité alimentaire médiocre, tandis qu'à des températures ambiantes élevées une évacuation plus rapide des calories excédentaires vers le milieu permet une ingestion alimentaire suffisante pour une croissance ou une ponte optimum, une qualité de coquille satisfaisante par le maintien de l'équilibre acido-basique, et une réduction de la mortalité par stress de chaleur.

Certains effets associés au gène Na n'ont pas encore d'interprétation claire, tel son effet dépressif sur le poids des femelles adultes aux températures basses ou tempérées. Une compensation légèrement insuffisante des dépenses énergétiques est suggérée par une réduction de la température corporelle de l'ordre de $0,2^{\prime \prime} \mathrm{C}$ chez les oiseaux "Cou nu » (Mérat 1986). Pour l'augmentation du pourcentage de muscles dans les carcasses, on peut se demander si davantage de protéines se trouvent disponibles par suite des besoins réduits pour la croissance du plumage.

La plus forte mortalité embryonnaire attachée au gène $\mathrm{Na}$ n'a pas été expliquée de manière satisfaisante. Selon Crawford (communication personnelle), cette mortalité est associée à de mauvaises positions des embryons, et l'absence de duvet sur le cou pourrait permet- 


\section{6 / Utilité potentielle du gène « Cou nu » en production avicole}

L'utilisation la plus vraisemblable du gène "Cou nu» se situe aux températures ambiantes élevées, $25^{\circ} \mathrm{C}$ et au-dessus. En production « chair », ses avantages sont alors une vitesse de croissance, un rendement à l'abattage et en viande supérieurs et une résistance meilleure aux stress de chaleur aigus. De plus, on peut prévoir une réduction du temps mis à plumer les poulets «Cou nu » avec moins de sicots, ainsi qu'un effet maternel légèrement positif sur la croissance précoce résultant d'un poids d'oeuf plus élevé si l'allèle $\mathrm{Na}$ est incorporé dans une lignée maternelle. Des travaux complémentaires devraient déterminer jusqu'à quel point les avantages observés pour les génotypes $\mathrm{Na} / \mathrm{Na}$ et $\mathrm{Na} / \mathrm{na}$ en chaleur constante sont conservés à des températures fluctuantes et dans quelle mesure ils sont influencés par le degré hygrométrique.

L'abaissement du taux d'éclosion pour les embryons « Cou nu » serait le seul effet défavorable associé au gène $\mathrm{Na}$ en ambiance chaude, mais cette perte pourrait être moindre dans des croisements de première génération qu'en lignée pure selon des observations de terrain. En outre, il faut rappeler en contre partie l'avantage relatif important des reproductrices «Cou nu» aux hautes températures quant à leurs performances de fertilité et d'éclosion. Le bilan d'ensemble pour le gène "Cou nu » apparaît clairement bénéficiaire pour la production "chair" en conditions climatiques chaudes (Mérat 1986 ; Mérat et al 1989).

Pour la ponte à température élevée, l'effet le plus important est la mortalité inférieure des poules «Cou nu» comparées aux poules na'/ na'; s'y ajoutent un poids moyen d'oeuf supérieur et vraisemblablement une meilleure qualité des coquilles et une ponte plus persistante. Ces avantages devraient aussi s'appliquer aux reproductrices « chair».

En ambiance tempérée, les poulets «Cou nu » sont évidemment inférieurs aux autres à $15-20^{\prime \prime} \mathrm{C}$ pour l'indice de consommation. Par contre, à $25^{\circ} \mathrm{C}$, une comparaison dans un croisement de type chair n'a fait apparaître aucune différence de croissance et d'efficacité alimentaire entre poulets «Cou nu » ou non (Mérat 1986). Dans ces conditions, l'avantage des oiseaux «Cou nu» pour leur rendement à l'abattage et en viande serait à comparer au coût supplémentaire du chauffage pour les maintenir à cette température et à la perte de taux d'éclosion attachée au gène $\mathrm{Na}$. Le bilan pourrait être favorable aux poulets « Cou nu » avec un âge d'abattage précoce qui réduit la durée du chauffage supplémentaire (Mérat 1986).

Pour la production d'oeufs, en combinaison avec le gène de nanisme $\mathrm{dw}$, le maintien d'une consommation alimentaire modérée par dw et un gain sur la ponte associé au génotype $\mathrm{Na}$ / $\mathrm{na}^{+}$conduisent à un bilan positif d'après les données citées. Des travaux ultérieurs seraient cependant nécessaires pour estimer de façon plus précise l'effet du génotype $\mathrm{Na} / \mathrm{na}^{-}$sur l'ef- ficacité alimentaire et sur la solidité des coquilles dans une lignée naine en conditions tempérées.

Plus généralement, des recherches sont justifiées pour connaître l'environnement (naturel ou artificiel) dans lequel le gène « Cou nu » serait le plus bénéfique pour la production de poulets de chair ou d'oeufs et pour évaluer l'intérêt économique de l'incorporation de l'allèle Na dans des lignées commerciales.

\section{6 / Plumage frisé (F), échanges énergétiques et performances}

Un autre gène susceptible de diminuer l'effet isolant du plumage est le gène frisé $(F)$. Il existe encore peu de données sur son incidence possible sur les caractères économiques. Selon Hutt (1949), l'éclosion des embryons frisés serait moins bonne et il y aurait un retard de maturité sexuelle et peut-être une mortalité plus élevée que pour le génotype normal. D'après le même auteur il y a une augmentation considérable du métabolisme énergétique pour les oiseaux à plumage frisé, ce qui suggèrait une réponse spécifique aux températures élevées; il en est de même de l'observation de moindres pertes par évaporation pour les « frisés ». Selon Horst (1987) et Haaren-Kiso et al (1988), en ambiance chaude le gène $F$ accroît le nombre et la masse des oeufs et réduit la mortalité par comparaison au génotype normal, et le double hétérozygote aux loci $\mathrm{F}$ et $\mathrm{Na}$ paraît favorisé pour la ponte. Cependant, Bordas et al (1990) n'ont pas trouvé de différences à cet égard entre le génotype hétérozygote $F / f$ et l'homozygote normal. Le résultat dépend peutêtre de conditions telles que le degré hygrométrique, l'importance relative du plumage ou son état d'usure en cages.

\section{7 / Emplumement lié au sexe (K), linkage avec le gène viral ev 21}

Des études anciennes concluaient à l'absence d'effet ou à un très léger effet dépresseur de l'allèle «emplumement lent» lié au sexe sur des paramètres de croissance ou de ponte. Dans les récentes années l'utilisation du gène $\mathrm{K}$, dominant, pour le sexage des poussins «chair » ou de pondeuses Leghorn là plumage blanc ne permettant pas le sexage par la couleur) a révélé des performances de ponte amoindries et une mortalité plus élevée consécutives à l'introduction de ce gène dans des lignées maternelles. Dans une comparaison de descendants de même génotype issus de mères $\mathrm{K}$ ou k', nous avons observé dans plusieurs lignées un retard de croissance et de maturité sexuelle associé au génotype maternel K. Lowe et Garwood (1981) ont trouvé un effet maternel négatif de l'allèle $\mathrm{K}$ sur le poids corporel à 40 semaines et la viabilité. Plus précisément, Harris et al (1984) ont observé une sensibilité plus élevée des filles de mères $K$ à la leucose; le génotype des filles avait aussi une influence,

\section{En climat tempéré, on pourrait tirer parti de l'effet favorable du gène "Cou nu " sur le rendement en viande à condition de minimiser la surconsommation alimentaire qu'il entraîne.}


les filles K étant les plus sensibles à une infection leucosique. Havrenstein et al (1987) trouvent également une ponte inférieure pour la descendance de mères $\mathrm{K}$.

Les travaux de Bacon et al (1985, 1986), dans

Parmi les gènes permettant de reconnaître le sexe des poussins, l'allèle

d'emplumement lent est associé à une moindre résistance

à la leucose chez la Leghorn. mais peut-être pas dans d'autres races.

des lignées Leghorn, ont montré un linkage de l'allèle $K$ avec un gène viral endogène (ev 21) qui peut interférer avec la réponse immunitaire de la descendance contre des virus leucosiques transmis par l'oeuf, ce qui permet d'expliquer la ponte et la viabilité inférieure de cette descendance. On n'a pas trouvé de différence associée aux allèles $\mathrm{K} / \mathrm{k}^{\prime}$ pour la réponse aux stress, la réponse immunitaire à d'autres antigènes, au virus de la maladie de Marek. Dunnington et al (1986) suggèrent un léger avantage des poussins $\mathrm{k}^{+}$sur ceux de génotype $\mathrm{K}$ pour la résistance à $E$. Coli.

\section{8 / Le complexe majeur d'histocompatibilité (locus B) : relation avec la résistance à des maladies particulières et les performances}

Il y a un vaste ensemble de travaux sur le complexe majeur d'histocompatibilité de la poule (locus B). Nous nous référons à des revues récentes sur ce sujet (Bumstead 1985; Hartmann 1986 ; Bacon 1987). D'autre part, les aspects spécifiquement immunologiques et pathologiques dépassent le cadre de cet article, limité à quelques résultats marquants sur le rôle du locus $B$ dans la résistance à des maladies particulières, et à quelques remarques générales quant à ses relations avec les caractères de production.

\section{1 / Résistance aux maladies}

Bacon (1987) cite 12 références montrant une association entre des haplotypes au locus B et la résistance ou la sensibilité à la maladie de Marek dans des croisements, des populations témoins ou des lignées consanguines, en présence d'une exposition naturelle ou artificielle. Il existe des effets sur la réponse à d'autres maladies: sarcomes, érythroblastose, leucose viscérale, affection thyroïdienne autoimmune, coccidiose (Eimeria Tenella), choléra aviaire. En ce qui concerne la maladie de Marek, les haplotypes B21 et B2 sont des facteurs de résistance, et les hétérozygotes B2/B21 sont plus résistants que les autres hétérozygotes porteurs de B21. Les allèles B19 et B15 montrent aussi une relative résistance.

Une découverte ayant une signification pratique possible est mentionnée dans la revue de Bacon (1987), à partir d'une comparaison entre génotypes $\mathrm{B}$ pour la résistance à la maladie de Marek et pour la transmission des virus leucosiques à l'œuf : les types résistants à la maladie de Marek ne coïncident pas nécessairement avec ceux qui déposent le moins de virus leucosiques dans les œufs. D'autre part, Gavora et Spencer (1979) ont montré qu'il y avait une cor- rélation positive entre la résistance d'un génotype à la maladie de Marek et sa réponse à la vaccination contre cette maladie, ce qui milite en faveur du maintien d'un effort de sélection pour la résistance à cette maladie, les vaccins n'étant pas efficaces à $100 \%$.

\section{2 / Relations avec des caractères de production}

Ces relations ont été recherchées depuis les travaux initiaux de Briles et collaborateurs, revus par Briles (1960), Gilmour (1960) et Nordskog (1964).

Pour des caractères et des populations variés, un avantage de l'état hétérozygote a été trouvé. La plupart du temps, ceci correspondait à l'infériorité de certains génotypes homozygotes. La majorité des comparaisons étaient faites à l'intérieur de lignées consanguines. L'avantage hétérozygote peut être au moins une partie de l'explication de la persistance de polymorphismes au locus $\mathrm{B}$ dans des lignées très consanguines (Briles et al 1957 ; Gilmour 1960).

Des croisements étant toujours utilisés au niveau de la production, la constatation ci-dessus n'a pas de conséquence pratique directe. Il n'en est pas de même de l'observation dans des populations non consanguines ou des croisements, de génotypes hétérozygotes particuliers ayant de meilleures performances que d'autres (Briles 1960, pour le taux d'éclosion: Allen et Gilmour 1962, pour le pourcentage de survie).

Des interactions sont apparues pour des paramètres de production entre des haplotypes au locus B et l'année (Briles 1964; Hardin 1971), la date d'éclosion (Briles 1964) et des gènes à d'autres loci (Morton et al 1965). Des différences de viabilité entre génotypes sont parfois inversées en fonction de l'âge (Briles et al 1957). De telles variations rendent difficile l'interprétation et l'utilisation d'effets attachés au locus B.

Selon Gavora et Spencer (1979), il existe une corrélation génétique négative entre la résistance à la maladie de Marek et le poids corporel et celui des ceufs, et une corrélation positive de cette résistance avec le nombre d'œufs. Si cela s'applique d'une façon générale aux haplotypes $B$, cette constatation peut servir de guide dans le choix de ces haplotypes.

On a avancé que les relations entre les génolypes au locus $B$ et des caractères de produclion reflétaient uniquement leur effet sur la morbidité (voir Briles 1964). Bacon (1987) remarque cependant que dans les années récentes l'utilisation d'animaux non contaminés, notamment vis-à-vis de la maladie de Marek, rend vraisemblable l'existence de relations avec des caractères de production indépendamment d'une infection. En outre, on peut noter que l'allèle B21, associé à une résistance à la maladie de Marek, n'est pas supérieur pour la production d'œufs selon Mc Dermid (1964) et Nordskog et al (1973).

Des effets maternels sur le taux d'éclosion et de survie ont été trouvés en relation avec des génotypes au locus B (voir Briles 1960). L'observalion par Bacon (1987) de différences entre 
génotypes B maternels pour le dépôt de virus leucosiques dans les ceufs devrait être prise en considération de ce point de vue.

\section{3 / Utilisation pratique}

Dans les années 1960, on s'est intéressé à l'utilisation des groupes sanguins dans des prourammes de sélection sur les performances économiques, mais cela n'a pas conduit à des applications pratiques durables. Ultérieurement, la connaissance d'effets sur la résistance i la maladie de Marek souleva une autre queslion. Après la mise en œuvre de vaccins, l'intérêt pour le locus B subsista avec: l'observation par Gavora el Spencer (1979) de différences génétiques pour la fréquence des échecs de vaccinations, en corrélation avec le degré de résistance à la maladie.

Comme Bacon (1987) l'a souligné, avant toute inclusion des génotypes au locus $\mathrm{B}$ dans un programme de sélection, une information nécessaire est l'identification des allèles les plus fréquents contenus dans les populations commerciales, afin d'éviter toute opposition entre les performances désirées et cette source de variabilité.

\section{9 / Gènes à effet métabolique influant sur la qualité sensorielle des produits}

Lorsque les pondeuses reçoivent une ration contenant plus de $10 \%$ de tourteau de colza, certains œufs ont une odeur « de poisson». Ceci est un problème économique non négligeable dans des pays où le colza est cultivé sur une échelle importante. Les populations contenant ce défaut sont essentiellement du type « œuf brun »,en particulier des lignées de race Rhode-Island Red. Dans ces populations, seuls certains individus produisent des œufs défectueux. Des études génétiques et physiologiques sur ce problème ont été passées en revue par Butler et Fenwick (1984). Bolton et al (1986) ont conclu qu'un gène autosomal semi-dominant (Eta) est responsable de l'odeur des oufs. Celleci est causée par la présence dans le jaune de triméthylamine, dérivée de la sinapine contenue dans le tourteau de colza ou de la choline. Chez les poules indemnes du défaut génétique, cette substance est oxydée par une enzyme, la triméthylamine-oxydase, et par suite dissoute et excrétée, mais chez les oiseaux affectés l'enzyme est déficiente.

L'éradication du gène défavorable a été envisagée comme la meilleure méthode permettant l'incorporation de colza dans les rations pour pondeuses à « œuf brun », puisque ces populations contiennent le gène « d'odeur » à des fréquences modérées et que celui-ci est partiellement dominant. Un test simple pour sa détection a été proposé par Mc Kay et Paton (1984): l'administration orale d'une dose de triméthylamine (TMA) à des animaux porteurs du gène inhibe leur appétit les jours suivants alors que les poules non-porteuses ne sont pas touchées. En conséquence, la perte de poids deux jours après l'administration de TMA différencie les deux types génétiques. Par ailleurs, il n'y a pas de raison évidente de supposer l'existence d'effets associés au gène Eta sur des caractères quantitatifs en l'absence de source de TMA dans l'aliment; en présence de TMA, produite par exemple suite à un apport de colza, on n'a pas vérifié l'effet à long terme sur l'ingestion alimentaire.

\section{0 / Conclusions générales}

Nous ferons en conclusion quelques remarques sur l'utilisation de gènes identifiés dans les programmes de sélection aviaires.

\section{1 / Situations favorables}

L'amélioration d'une performance économique à l'aide de facteurs mendéliens est un cas de sélection indirecte. Une telle sélection sera particulièrement utile si aucun gain génétique n'est attendu d'une sélection quantitative directe $(G=0)$. G étant proportionnel à l'intensité de sélection (i) et à l'héritabilité du caractère $\left(h^{2}\right)$, le tableau 9 résume les situations favorables à l'application d'une sélection indirecte, y compris grâce à des facteurs mendéliens.

Des effets de gènes individuels relatés dans la littérature correspondent aux situations contenues dans le tableau 9: ainsi $\mathrm{Na}$ améliorant le rendement des carcasses et l'adaptation à des températures élevées, des allèles du locus $\mathrm{B}$ conférant une résistance à des agents pathogènes spécifiques, $\mathrm{dw}$ en sélection «chair » supprimant les effet d'une corrélation défavorable entre la vitesse de croissance et le poids adulte. L'utilisation du gène dw dans la production d'œufs pourrait, elle, éviter des réponses liées non désirables dans une sélection à long terme pour une taille corporelle réduite.

Une autre nécessité est l'importance suffisante des effets d'un gène individuel sur les caractères quantitatifs recherchés. Si la sélection usuelle sur les caractères économiques plafonne, des gènes précédemment négligés peuvent devenir utiles; tel est, peut-être, pour la production d'œufs, le gène "crête en pois » avec l'amélioration de l'efficacité alimentaire de $2 \%$ qu'il apporte.

Enfin, les effets d'un gène, pour être utilisables, doivent être constants, au moins dans des conditions précisées.

\section{2 / Conséquences de la fréquence d'un gène majeur dans des lignées commerciales}

Augmenter la fréquence d'un gène dans une lignée commerciale pose évidemment moins de problèmes s'il y est déjà présent. Inversement, l'éradication d'un gène indésirable est relativement simple. L'absence d'un allèle utile dans des lignées commerciales courantes nécessite son introduction à partir de populations supposées avoir un niveau inférieur de performances, suivie de croisements de retour répétés à la lignée améliorée. De ce point de vue l'identification facile des génotypes hétérozygote et 
Tableau 9. Situations favorables à une sélection indirecte (d'après Mérat 1978).

\begin{tabular}{|c|c|}
\hline $\begin{array}{c}\text { Motifs pour l'emploi } \\
\text { d'une sélection indirecte }\end{array}$ & Exemple \\
\hline $\begin{array}{l}\text { (a) i = } 0 \text { (intensité de sélection nulle) } \\
\text { (ai) caractère coûteux ou difficile à mesurer } \\
\text { (a2) environnement coûteux ou difficile à obtenir } \\
\text { (a3) présence de corrélations } \\
\text { génétiques défavorables } \\
\text { (b) i } \neq 0, h^{2}=0 \\
\text { non-additivité de la variance génétique } \\
\text { restante (ex. : overdominance) }\end{array}$ & $\begin{array}{l}\text { Efficacité alimentaire ; rendement des carcasses } \\
\text { Résistance à des maladies spécifiques : } \\
\text { adaptation à un climat exotique (ex. : chaleur) } \\
\text { Croissance rapide et efficacité alimentaire } \\
\text { de la reproductrice }\end{array}$ \\
\hline
\end{tabular}

homozygote, comme dans le cas du gène « Cou nu », est un avantage. Comme pratiquement tous les produits commerciaux sont issus de croisements, l'utilisation d'un gène récessif au niveau d'un croisement terminal nécessiterait la présence de ce gène dans toutes les lignées parentales. L'utilisation du gène $\mathrm{dw}$ dans des croisements "chair » est une situation différente puisque l'expression du gène est désirée seulement au niveau du parent maternel.

\section{3 / Utilisation optimale d'un gène majeur selon l'ensemble de ses effets et les facteurs conditionnant son expression}

Il est nécessaire d'optimiser l'emploi d'un gène, car il est rare que tous ses effets soient positifs, et son expression dépend souvent du contexte génétique, de l'environnement ou des deux. Ceci implique d'inventorier les effets d'une mutation sur tous les aspects de la valeur économique de l'animal. Cette nécessité n'est pas particulière aux facteurs mendéliens; la race Cornish, à l'origine de nos lignées «mâle chair », n'avait pas de qualités exceptionnelles de reproduction, mais elle a cependant été largement utilisée du fait de ses autres avantages.

Des exemples d'expression variable d'un gène potentiellement utile selon le reste du génome ou l'environnement ont déjà été mentionnés, par exemple les effets du gène dw sur la ponte et l'efficacité alimentaire en fonction du format de la population de départ, ou les interactions entre le gène " Cou nu » et la température ambiante pour de nombreux caractères.

Par suite, l'usage d'un gène peut être optimisé en le restreignant aux contextes génétiques et aux environnements où il a le plus de chances d'être bénéfique. Une manière de le faire est en particulier de compenser ou limiter les effets indésirables associés à un mutant par les effets additifs d'autres gènes ou de facteurs du milieu, telle l'introduction du gène $d w$ en vue de la ponte dans des lignées sélectionnées pour un poids d'œuf élevé relativement au poids corporel. On peut aussi rechercher l'existence d'effets favorables non additifs; ainsi de l'utilisation conjointe de deux allèles au locus B dont chacun apporterait une résistance dominante à un agent pathogène différent, ou d'une interaction entre les gènes $\mathrm{dw}$ et $\mathrm{Na}$ pour le taux de ponte et l'efficacité alimentaire.

\section{4 / Quelles catégories de gènes rechercher?}

Le nombre de gènes identifiés individuellement et potentiellement utiles est actuellement limité. Quelques suggestions pour en trouver de nouveaux peuvent être proposées. Des gènes en rapport avec toute réaction vis-à-vis d'agents pathogènes sont des candidats évidents : gènes de réponse immunitaire, gènes contrôlant des récepteurs à un agent pathogène déterminé, gènes viraux endogènes, ou même certains variants de protéines ou d'enzymes. De nouvelles recherches sont nécessaires sur les polymorphismes enzymatiques en relation avec l'utilisation de sources alimentaires contenant des facteurs antinutritionnels ou subtoxiques; il semble y avoir plus de perspectives pour une telle recherche que dans le domaine de la variation génétique des besoins ou de l'utilisation des nutriments essentiels. Plus d'attention pourrait également être portée à la composition des œufs et des carcasses ; des mutations affectant des protéines ou des enzymes pourraient être prises en considération à cet égard. Les gènes reconnus par un effet visible ont été examinés surtout pour leur influence sur la taille corporelle et sur le métabolisme énergétique ; le comportement et l'activité, qui influent sur la consommation alimentaire, pourraient être affectés par des gènes ayant des effets majeurs sur les systèmes nerveux et locomoteur.

Cet article est adapté, pour l'essentiel, de Mérat P. 1990. Pleiotropic and associated effects of major genes. In Crawford R.D. (Ed.), Poultry Breeding and Genetics, 429-467. Elsevier, Amsterdam. 


\section{Références bibliographiques}

ABBOTT U.K., 1958. Selection for viability in scaleless chickens. Proc. 11th Pacific Chicken and Turkey breeders Roundtable (Pullman).

ABBOTT U.K., ASMUNDSON V.S., 1962. Response to selection under severe environmetnal stress. Proc. 12th World's Poultry Cong. (Sydney), 30-36.

ALLEN C.P., GILMOUR D.G., 1962. The B blood group system of chickens. III. The effects of two heterozygous genotypes on the survival and egg production of multiple crosses. Genetics 47 : 1711-1718.

BACON L.D., 1987. Influence of the Major Histocompatibility complex on disease resistance and productivity. Poultry Sci. 66 : 802-811.

BACON L.D., SMITH E.J., CRITTENDEN L.B., HAVENSTEIN G.B., 1985. Association of genes determining slowfeathering $(\mathrm{K})$ and an endogenous virus (ev 21) on the $\mathrm{Z}$ chromosone. Poultry Sci. 64 (suppl. 1) : 60.

BACON L.D., FADLY A.M., CRITTENDEN L.B., 1986. Absence of influence on immune competence by the sexlinked gene $(\mathrm{K})$ determining slow-feathering in White Leghorn chickens. Avian Dis. 30 : 751-760.

BARRIO L., FRAGA L.M., PEREZ P., 1987. Influence of the naked neck gene $(\mathrm{Na})$ on the incidence of pecking and cannibalism in light layers. Cuban J. Agric. Sci. 21: 285-289.

BOLTON N., CARTER T.C., MORLEY JONES R., 1976. The hen's egg : genetics of taints in eggs from hens. fed on rapeseed meal. Brit. Poult. Sci. 17 : 313-320.

BORDAS A., MERAT P., 1981. Genetic variation and phenotypic correlations of food consumption of laying hens corrected for body weight and production. Brit. Poult. Sci. $22: 25-33$.

BORDAS A., MERAT P., 1990. Croissance, production d'oeufs et efficacité alimentaire de poulets et de poules hétérozygotes $\mathrm{Ff}+$ (plumage frisé) ou $\mathrm{f}+\mathrm{f}+$ (non frisé) à température ambiante élevée. Archiv Geflügelk. 53 (sous presse]

BRILES W.E., 1960. Blood groups in chickens, their nature and utilization. World's Poultry Sci. J., 16: 228242.

BRILES W.E., 1964. Current status of blood groups in domestic brids. Zeitschr. Tierzücht. Züchtungs. 79 : 371391.

BRILES W.E., ALLEN C.P., MILLEN T.W... 1957. The B blood group system of chickens. I. Heterozygosity in closed populations. Genetics $42: 631-648$.

BUMSTEAD N., 1985. Genetics of the Major Histocompatibility complex in chickens. In Poultry Genetics and Breeding, ed. W.G. Hill, Manson, J. M. Hewitt, D. 25-35. Brit. Poult. Sci, Longman, Harlow.

BUTLER E.J., FENWICK G.A., 1984. Trimethylamine and fishy taint in eggs. World's Poult. Sci. J., 40 : 38-51;

CRAWFORD R.D., 1977. Naked neck transmission ratios and embryo survival in domestic fowl. Poultry Sci. 56: 1706 (Abstract.)

DUNNINGTON, E.A., SIEGEL P.B., GROSS W.B., 1986. Sex-linked feathering alleles $(\mathrm{K}, \mathrm{k}+)$ in chickens of diverse genetic backgrounds. 2. Resistance to Escherichia coli. Avian Path. 15, 139-148.

FRAGA L.M., LAM P.T., 1987. A study of the naked neck gene in the productive traits of semi-light layers. Cuban J. Agric. Sci. $21: 69-73$.

GAVORA J.S., SPENCER J.L., 1979. Studies on genetic resistance of chickens to Marek's disease. A review. Comp. Immun. Microbiol. Infect. Dis. 2 : 359-371.

GILMOUR D.G., 1960. Blood groups in chickens. Brit. Poultry Sci. $1: 75-100$.

HAAREN-KISO A.V., HORST P., VALLE-ZARATE A., 1988. The effect of the frizzle gene (F) for the productive adaptability of laying hens under warm and temperate environmental conditions. Proc. 18th World's Poultry Cong. (Nagoya), 386-388.

HAMMADE H., PETITJEAN M., DOUAIRE M., MALLARD J., MERAT P., 1987. Effet du gène Na (" Cou nu ») chez des coqs élevés à deux températures. II. Caractéristiques du sperme et reproduction. Gnét. Sél. Evol. 19 : 365ques
380.
HARDIN R.T., 1971. Relationships between blood group alleles at the B- locus and economic traits in a population of non-inbred meat-type chickens. Poultry Sci. 50: 12611270

HARRIS D.L., GARWOOD V.A, LOWE P.C., HESTER P.Y., CRITTENDEN L.B., FADLY A.A., 1984. Influence of sex-linked feathering phenotypes of parents and progeny upon lymphoid leukosis virus infection status and egg production. Poultry Sci. 63 : 401-413.

HARTMANN W., 1972. Relationships between genes at the pea and single comb locus and economic traits in broiler chicken. Brit. Poultry Sci. 13 : 305-309.

HARTMANN W., HALA K., HEIL G., KRIEG R., 1986. Effects of $B$ blood group genotypes on resistance to Marek's disease in Leghorn crosses. 7e Conf. Avic. europ. (Paris), 1, 216-220.

HAVENSTEIN G.B., TOMMER R.H., TOELLE V.D., EMSLEY A., 1987. Fffetc of genetic strain, slow versus rapid feathering maternal genotype, and cage density on the performance of SCWI's. Poultry Sci. 66 (suppl.) : 114.

HERREMANS M., ABD-EL-AZIM A., MERAT P., DECUYPERE E., 1988. Some physiological, morphological and production parameters associated with the naked neck gene $(\mathrm{Na}$ ) in dwarf (dw) laying hens. Archiv Geflügelk. $52,181-187$.

HORST P., 1982. Genetical perspectives for poultry breeding of improved productive poultry in tropical conditions. proc. 2nd World's Cong. Genet Appl. Livestock Prod. (Madrid) 8, 887-892.

HORST P., 1987. Animal genetic resources and potential for resource development in the tropics with special reference to Malaysia. Malaysian Appl. Biol. 16 : 13-22.

HORST P., RAUEN H.W., 1986. Significance to the naked neck gene (Na-gene) in poultry breeding in the tropics. 7e Conf. Avic. Europ. (Paris) 1, 191-195.

HUTT F.B., 1949. Genetics of the Fowl. Mc Graw-Hill Book Co. Inc. New-York.

HUTT F.B., COLE R.K., 1973. Identification of sex in chicks by the way of the gène $s^{\text {nll }}$. Poultry Sci. 52, 2044 (Abstract)

LOWE P.C., GARWOOD V.A., 1981. Independent effects of $\mathrm{K}$ and $\mathrm{k}+$ alleles and maternal origin on mortality and performance of crossbred chickens. Poultry Sci. 60 : 1123-1126.

MC KAY J.C., PATON I.R., 1984. Genetics of egg tainting, 17 th World's Poult. Cong., Helsinki, 157-158.

Mc DERMID F.M., 1964. The effect of blood group genotypes of the $B$ system on the performance of hybrid chickens. Proc. 9th Europ Anim. Blood Group Conf. (Prague), 173-178.

MERAT P., 1986. Potential usefulness of the Na (Naked neck) gene in poultry production. World's Poultry Sci. J ; 42, 124-142.

MERAT P., 1990. Pleiotropic and associated effects of major genes. In Crawford R.D. (Ed.), Poultry Breeding and genetics, 429-467. Elsevier, Amsterdam.

MERAT P., BOICHARD M., BORDAS A., COQUERELLE G., 1989. Réponse à la chaleur des génotypes $\mathrm{Na} / \mathrm{Na}$ (Cou nu) et nat/na+ (plumage normal) pour le taux de fertilité et d'éclosion de la poule reproductrice. Archiv Geflügelk. $53: 185-191$

MERAT P., BORDAS A., 1990. Differential response of sex-linked albino ( $\left.\mathrm{s}^{\mathrm{n}}\right)$ and silver (S) hens to high and low light intensity. Brit. Poult. Sci. 30:809-815.

MERAT P., BORDAS A., COQUERELLE G., 1986. Caractéristiques de croissance, ponte et efficaicté alimentaire associées au gène $\mathrm{s}^{\mathrm{ul}}$ (albinos lié au sexe) chez la poule domestique. Génét. Sél. Evol. 18 : 343-350.

MERAT P., BORDAS A., IONON F, PERRAMON A., 1981. Effets quantitaifs associés au gène albinos lié au sexe chez la caille japonaise.Ann. Génét. Sél. Anim. 13:7592

MORTON J.R., GILMOUR D.G., DERMID E.M. Mc, OGDEN A.L., 1965. Association of blood group and protein polymorphisms with embryonic mortality in the chicken. Genetics 51: 97-107. 
NORDSKOG A.W., 1964. Poultry immunogenetics. World's Poultry Sci. J. 20 : 183-188.

NORDSKOG A.W., RISHELL. W.A., BRIGGS D.M., 1973. Influence of B-locus blood groups on adult mortality and egg production in the White Leghorn chicken. Genetics $75: 181-189$

RAUEN H.W., 1985. Auswirkungen des Gens für Befiederungsreduktion und Nackthalsigkeit [Na-Gen) auf das produktive Adaptations-vermögen von Legehennen an hohe Umwelttemperaturen. Thèse Univ. Berlin.

RAUEN H.W., HORST P., VALLE-ZARATE A., 1986. Bedeutung des gens für Befiederungsreduktion und Nackthalsigkeit ( $\mathrm{Na}$ ) für das produktive Adapatationsvermögen von Legehennen unter hoher Temperatur Dauerbelastung. Archiv Geflügel., 50 : 235-245.

DE REVIERS M., 1982. Différents aspects de l'élevage des reproducteurs mâles (coqs, pintades) utilisés en insémination artificielle. In "Fertilité et insémination artificielle en Aviculture ", ed. INRA, Versailles, 25-60.
SILVERSIDES F.G., CRAWFORD R.D., 1986. The effect of sex-linked imperfect albinism on female broiler performance. Poultry Sci. 65 (suppl. 1) : 125.

SILVERSIDES F.G., CRAWFORD R.D., 1987. The effect of sex-linked imperfect albinism $\left(\mathrm{s}^{\text {al }}\right)$ on egg production in chickens. Poultry Sci. 66 (suppl. 1) : 176

SMITH L.T., LEE R., 1977. A study of the naked neck gene of the fowl. Poultry Sci. 56:1758 (abstract).

SMYTH J.R., BOYLE M.L. III, DAMIEN S.M., PARDUE S.L., 1987. Relationships between hypomelanic mutations and early development of the chick. Poultry Sci. 66 (suppl. 1) : 180 .

SOMES R.G., Jr. 1975. Pleiotrophic effects of the sex-linked delayed feathering gene, Kn, in the chicken. Poultry Sci. $54: 208-216$

STURKIE P.D., 1965. Avian Physiology, $2^{\mathrm{e}}$ ed. Comstock publ. Assoc. Ithaca, New-York.

\section{Summary}

Associated effects and utilization of major genes other than these reducing body size in the fowl.

Besides genes influencing body size, the associated effect and possible usefulness of other identified genes of the domestic fowl were investigated. Several sex-linked genes (plumage color, feathering) allow visual sexing of day-old chicks, which represented the first practical application of Mendelian factors in poultry production. The pea-comb gene lowers heat dissipation through naked head appendages, reduces feed consumption of layers and improves their feed conversion rate by $2 \%$. Several genes suppressing pigment in the plumage have similar effects, i.e. slight depression of body weight and improvement of feed efficiency for egg production, better plumage condition toward the end of the laying year. The sex-linked albino allele, besides allowing day-old sexing in appropriate crosses, was found superior to the $S$ colored gene for egg production with controlled lighting intensity (low during rearing, high during production). The naked neck gene, which suppresses 30 to $40 \%$ of the plumage, has positive effects on meat yield; by increasing heat dissipation it causes a poor feed efficiency at low or moderate ambient temperatures $\left(20^{\circ} \mathrm{C}\right.$ or below) but above $25^{\circ} \mathrm{C}$ and mainly above $30^{\circ} \mathrm{C}$ it has a beneficial effect on growth rate, viability (especially during heat stress), egg weight and female reproductive performance.
Its incorporation in crosses for production in hot climates could be justified. The Frizzle gene, which also is likely to increase the heat exchange of the bird, does not have such marked effects on production traits. A slow feathering sex-linked allele, used for sexing, has been found linked with a "viral gene " in the Leghorn breed, hence a higher risk of leukosis infection through the egg of dams having this gene. For the Major Histocompatility Complex (B-locus), particular genotypes are associated with resistance or susceptibility to Marek's disease, against which vaccines are not $100 \%$ successful. The question may be raised of the choice of specified alleles in this perspective. Finally a single gene is responsible for a fishy egg taint in some brown-egg type laying stocks when rapeseed meal is incorporated into feeds. Its eradication in these populations was suggested.

The utilization of Mendelian factors in selection programmes may concern particular traits for which direct selection is difficult or costly, or environments which are difficult to realize for the breeder. When a new major gene is introduced, the optimal conditions for its use are to be looked for, as it may be necessary to correct for some of its effects.

MERAT P., 1990. Gènes majeurs chez la poule (Gallus Gallus): autres gènes que ceux affectant la taille. INRA Prod. Anim., 3 (5), 355-368. 